\title{
Targeting CD44 by CRISPR-Cas9 in Multi- Drug Resistant Osteosarcoma Cells
}

\author{
Zheng Xiao Jia Wan ${ }^{a}$ Ayub Abdulle Nurc Pencheng Dou ${ }^{a}$ Henry Mankinc \\ Tang Liu ${ }^{a, c} \quad$ Zhengxiao Ouyang ${ }^{a}$ \\ aDepartment of Orthopedics, The Second Xiangya Hospital, Central South University, Changsha, \\ ${ }^{b}$ Department of Nephrology, The Second Xiangya Hospital, Central South University, Key Laboratory \\ of Kidney Disease and Blood Purification in Hunan, Changsha, 'Department of Orthopedic Surgery, \\ Massachusetts General Hospital and Harvard Medical School, Boston, USA
}

\section{Key Words}

Osteosarcoma $\cdot$ CRISPR-Cas9 $\cdot \mathrm{CD} 44 \cdot$ Drug resistance $\cdot$ Gene therapy

\begin{abstract}
Background/Aims: Drug resistance is the main difficulty for the current treatment for osteosarcoma. Cluster of differentiation 44 (CD44) is a receptor for hyaluronic acid (HA) and HA-binding has been proven to participate in various biological tumor activities, including tumor progression, metastasis and drug resistance. In this study, we aimed to determine the effects of CD44 on migration, invasion, proliferation, and the drug-sensitivity of osteosarcoma. Methods: 96 human osteosarcoma tissues from 56 patients were collected to evaluate the expression of CD44 in osteosarcoma tissue by immunohistochemistry. CRISPR-Cas9 system was used to specifically silence CD44 in drug-resistant cell lines (KHOSR2 and U-2OSR2). The migration and invasion activities of cells was demonstrated by wound healing and transwell invasion assay. The proliferation speed of the cells was detected under 3D cell culture condition. Drug resistance of cells was detected by MTT and drug uptake assay. Results: The immunohistochemistry results demonstrated that a high level of CD44 may predict poor survival and higher potential of metastasis, recurrence and drug resistance in patients with osteosarcoma. After knocking-out of CD44 by the CRISPR-Cas9 system, not only the migration and invasion activities of osteosarcoma cells were significantly inhibited, but the drug sensitivity was also enhanced. Conclusion: CD44 silencing could inhibit the development of osteosarcoma migration, invasion, proliferation and ameliorate drug resistance to current treatment in osteosarcoma. This study applies new strategy to target CD44, which may improve the prognosis of osteosarcoma.




\section{Cellular Physiology Cell Physiol Biochem 2018;51:1879-1893

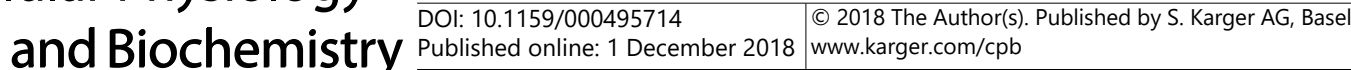 \\ Xiao et al.: Targeting CD44 in Osteosarcoma}

\section{Introduction}

Osteosarcoma is the most common primary malignant bone tumor that occurs mostly in adolescence $[1,2]$.Standard treatment consists of surgical resection of primary and pulmonary lesions in combination with multi-agent chemotherapy regimens. Diseasefree survival of localized osteosarcoma increased from $<20 \%$ prior to the introduction of effective chemotherapy to around $60 \%$, and overall survival was increased to $60-70 \%[3,4]$. However, the current main chemotherapeutic agents used for the treatment of metastatic and recurrent osteosarcoma have a limited efficacy and the long-term survival for osteosarcoma patients with metastases is only $20 \%$. Furthermore, the ability to predict the prognosis of osteosarcoma is limited at present. Hence, it is urgent to identify prognostic markers to further evaluate survival in patients with osteosarcoma.

Cluster of Differentiation 44 (CD44) is a group of cell adhesion molecules. It is involved in the specific adhesion between cell surface and the extracellular matrix by binding to hyaluronic acid (HA)[5]. Interaction of HA and CD44 activate several oncogenic pathways such as the mitogen activated protein kinases (MAPK) and PI3 kinases/akt pathways, consequently leading to tumor cell migration, invasion, proliferation, and chemotherapy resistance in solid cancers [6]. Previous studies showed that CD44 was overexpressed in a variety of different malignant cancers $[7,8]$. And CD44 silencing significantly restored the sensitivity to chemotherapy in ovarian cancer cells [8]. Furthermore, CD44 protein has been found to be widely expressed in multiple osteosarcoma cell lines and be significantly up-regulated in metastatic and recurrent osteosarcoma tissues [9]. CD44 up-regulation also increases epithelial to mesenchymal transition (EMT), contributing to tumor metastasis, and leading to a worse prognosis for osteosarcoma [10].

P-glycoprotein (P-gp), encoded by MDR1 gene, is an energy-dependent drug efflux pump that pumps out many structurally unrelated chemotherapeutic drugs. P-gp overexpression plays an important role in resistance to a variety of anti-cancer drugs, such as vinblastine, doxorubicin and paclitaxel $[11,12]$. Furthermore, studies demonstrated that P-gp plays a significant role in metastasis of lung, colon and liver cancers [13-15] . A previous study showed that P-gp protein is physically associated with CD 44 protein by their co-immunoprecipitation and co-localization within the cell membrane [16]. In addition, it has been confirmed that CD44 interacts with P-gp in yeast two-hybrid system [17].

In most studies exploring the biological function of CD44 in the osteosarcoma, siRNA was applied to knock down CD44[18]. But the knockdown of transcribed mRNA due to siRNA is temporary, and the further clinical application of siRNA is limited. Recently, the clustered regularly interspaced short palindromic repeats (CRISPR)-associated 9 (Cas9) nuclease system has been used for the modification of target genes [19]. Among three identified types (I-III) of CRISPR systems, Type II CRISPR system is one of the best characterized. The Type II CRISPR system is composed of nuclease Cas9, CRISPR RNA (crRNA) array that is derived from exogenous DNA, and an auxiliary transactivating crRNA (tracrRNA) which is required to facilitate the treatment of crRNA arrays into discrete units [20]. CrRNA and tracrRNA can be fused together to produce chimeric unidirectional RNA (sgRNA)[21]. In addition, sgRNA can direct Cas 9 protein to cleave the double-stranded DNA at the target point of the crRNA boot sequence and produce double-strand breaks (DSBs) [22, 23]. After formation of DSBs, insertions and deletions (indels) are produced, leading to the target gene destruction [24]. Due to the good targeting ability of CRISPR-Cas9 system, and its higher efficiency when compared with siRNA, it is a revolutionary development in the field of genetic engineering. CRISPR-Cas9 possesses an enormous latent capacity to makes up for the limitations of the traditional genome editing techniques [23]. Furthermore, the CRISPR/Cas9 machinery has been successfully used to edit the genome of osteosarcoma cells recently [25].

In this study, we first examined the expression of CD44 in osteosarcoma tissues and then used CRISPR-Cas9 gene editing techniques to knockout CD44 in two drug-resistant cell lines (KHOSR2 and U-2OSR2) to investigate the role of CD44 in the migration, invasion, proliferation and drug-resistance of osteosarcoma. 


\section{Cellular Physiology Cell Physiol Biochem 2018;51:1879-1893 \begin{tabular}{l|l|l} 
and Biochemistry Published onlıne: 1 December 2018 & $\begin{array}{l}\text { (c) } 2018 \text { The Author(s). Published by S. Karger AG, Basel } \\
\text { www.karger.com/cpb }\end{array}$ \\
\hline
\end{tabular} \\ Xiao et al.: Targeting CD44 in Osteosarcoma}

\section{Materials and Methods}

\section{Human osteosarcoma tissues}

The formalin-fixed, paraffin-embedded tumor specimens of 97 osteosarcoma tissues from 56 patients were selected from The Second Xiangya Hospital of Central South University. The specimens were made into hematoxylin and eosin-stained slides and then were read by a pathologist, together with pathology reports which conclude representative triplicate 0.5 -mm-diameter core biopsies. Clinical information of all the subjects was collected, including age, gender, tumor location, tumor stage (primary/metastasis/recurrent), whether the patient received pre-operative chemotherapy or not, the tumor necrosis percentage (if the patient received chemotherapy, and the follow-up period (Table 1, Table2). Institutional Review Board (IRB) approval was obtained from the Second Xiangya Hospital of Central South University to collect all osteosarcoma samples. Written informed consent was obtained from all patients whose specimens and clinical information were used for this research study. All experimental protocols were approved by ethics committee of the Second Xiangya Hospital of Central South University (IRB protocol number: S031). The methods described in this study were carried out in accordance with the approved guidelines.

\section{Immunohistochemistry}

To observe the expression of CD44 protein in human osteosarcoma tumor tissue, immunohistochemical staining was conducted according to immunohistochemistry protocol from Cell Signaling Technology. First, the paraffin tissue was sliced into thin slices of $4 \mu \mathrm{M}$ with paraffin slicing machine. Then the dry tissue slices were deparaffinized in xylene for 10 minutes and rehydrated in graded ethanol $(100 \%, 95 \%, 90 \%, 85 \%$, $80 \%, 75 \%, 60 \%, 50 \%, 30 \%$ ). Next, the slides were subjected to $0.01 \mathrm{~mol} / \mathrm{L}$ citrate buffer at a temperature of $100^{\circ} \mathrm{C}$ for 10 minutes, washed three times with PBS and then incubated with $5 \%$ bovine serum albumin (BSA) for 20 minutes to inhibit nonspecific binding of IgG. Subsequently, the primary antibody was added to the tissue slide. After being incubated at $37^{\circ} \mathrm{C}$ for 2 hours, the tissue slide was washed 3 times with PBS. Then the tissue slide was incubated with Polyperoxidase-anti-mouse/rabbit IgG at $37{ }^{\circ} \mathrm{C}$ for 2 hours, washed 3 times with PBS. In order to determine the appropriate coloration time, DAB solution was added to the slice. After dyeing successfully, the tissue slide was rinsed for 10 minutes by running water to stop the reaction. Finally, the labeled slides were analyzed by a fluorescence microscope (Olympus America Inc., Melville, NY). The immunostaining intensity pattern of CD44 was evaluated in a semi-quantitative manner as follows: 0 , nostaining; $1+$, weak staining; $2+$, moderate staining; and $3+$, intense staining.

\section{Human osteosarcoma multiple drug resistance cell lines}

The human osteosarcoma cell line KHOSR2 is provided by Dr. Efstathios Gonos (Institute of Biology and Biology, Athens, Greece). And U-20SR2 cells were obtained from the American Type Culture Collection (Rockville, Maryland, USA). These cell lines were cultured in RPMI 1640 (Life Technologies, Grand Island, NY, USA) supplemented with 10\% FBS, 100 units/mL penicillin, and 100 $\mu \mathrm{g} / \mathrm{mL}$ streptomycin (Life Technologies, Grand Island, NY,USA) [58]. Cells were cultivated in a humidified atmosphere consisting of 5\% CO2 and $95 \%$ air.

\section{CRISPR-Cas9 plasmid design and purification}

Aiming at the RNA sequence of CD44-U6-gRNA-Cas9 \pm 2A-GFP plasmid (abbreviated asCD44-Cas9GFP) was constructed to targeted knockout CD44. The plasmid was purchased from Horizon Discovery. Green fluorescent protein (GFP) and Cas9 protein are co-expressed in mRNA and connect with each other through the $2 \mathrm{~A}$ peptide bond to determinate transfection efficiency. The designated target of the plasmid/ sgRNA is located on the first coding exon of the CD44 gene. The sequence of CD44 sgRNA is as follows: 5 '- CGATCTGCGCCAGGCTCAG - 3' (Fig. 1). The pEGFP-N3 plasmid was provided by Clontech Laboratories, Inc. (Mountain View, CA, USA). The extraction of the plasmid was carried out by QIAGEN Plasmid Mega Kits (Hilden, Germany) following the Plasmid Purification Handbook.

Table 1. Histological response to pre-operative chemotherapy and CD44 immunostaining. ${ }^{*}$ Good response: $\geq 90 \%$ necrosis; Poor response: $<90 \%$ necrosis

\begin{tabular}{lcccc}
\hline & Good response & Poor response & No preoperative chemotherapy & Total \\
\hline CD44 high staining & 8 & 9 & 2 & 19 \\
CD44 low staining & 30 & 6 & 1 & 37 \\
Total & 38 & 15 & 3 & 56 \\
\hline
\end{tabular}


We measured the DNA concentration at $260 \mathrm{~nm}$ using UV spectrophotometry and made quantitative analysis on the agarose gel to determine the yield of the plasmid.

Work flow of transfection of CD44sgRNA-Cas9-GFP mediated by Lipofectamine

The CD44 sgRNA-Cas9-GFP plasmid was transfected into U-20SR2 cells and KHOSR2 cells via lipofectin according to Lipofectamine ${ }^{\circledR} 3000$ reagent procedure. Firstly, U-20SR2 cells and KHOSR2 cells were inoculated into 12-well plates at a density of $1.0 \times 10^{5}$ cells $/ \mathrm{mL}$. After 24 hours, the cells were rinsed three times with Opti-MEM $®$ Medium reagent, and then cultured in supplemented $1 \mathrm{~mL}$ serum-free medium. Secondly, $1.5 \mu \mathrm{L}$ Lipofectamine ${ }^{\circledR} 3000$ reagent was diluted to $50 \mu \mathrm{L}$ Opti-MEM® Medium, $1 \mu \mathrm{g}$ recombinant DNA was mixed with $500 \mu \mathrm{LOpti}-\mathrm{MEM} \circledast$ Medium, and $2.0 \mu \mathrm{L}$ P3000 ${ }^{\mathrm{Tm}}$ Reagent was added to the diluted recombinant DNA. Thirdly, the diluted recombinant DNA was mixed with the diluted Lipofectamine ${ }^{\circledR} 3000$ mixture (1: 1 ratio). After incubation at room temperature for 5 minutes, the transfection reagent and the recombinant DNA mixture were added to U-20SR2 cells and KHOSR2 cells wells. After incubated for 48 hours, the cells that were successfully transfected with CD44 sgRNA-Cas9-GFP plasmid were screened by flow cytometry and were cultured and amplified for further study. While the untransfected cells were served as control.

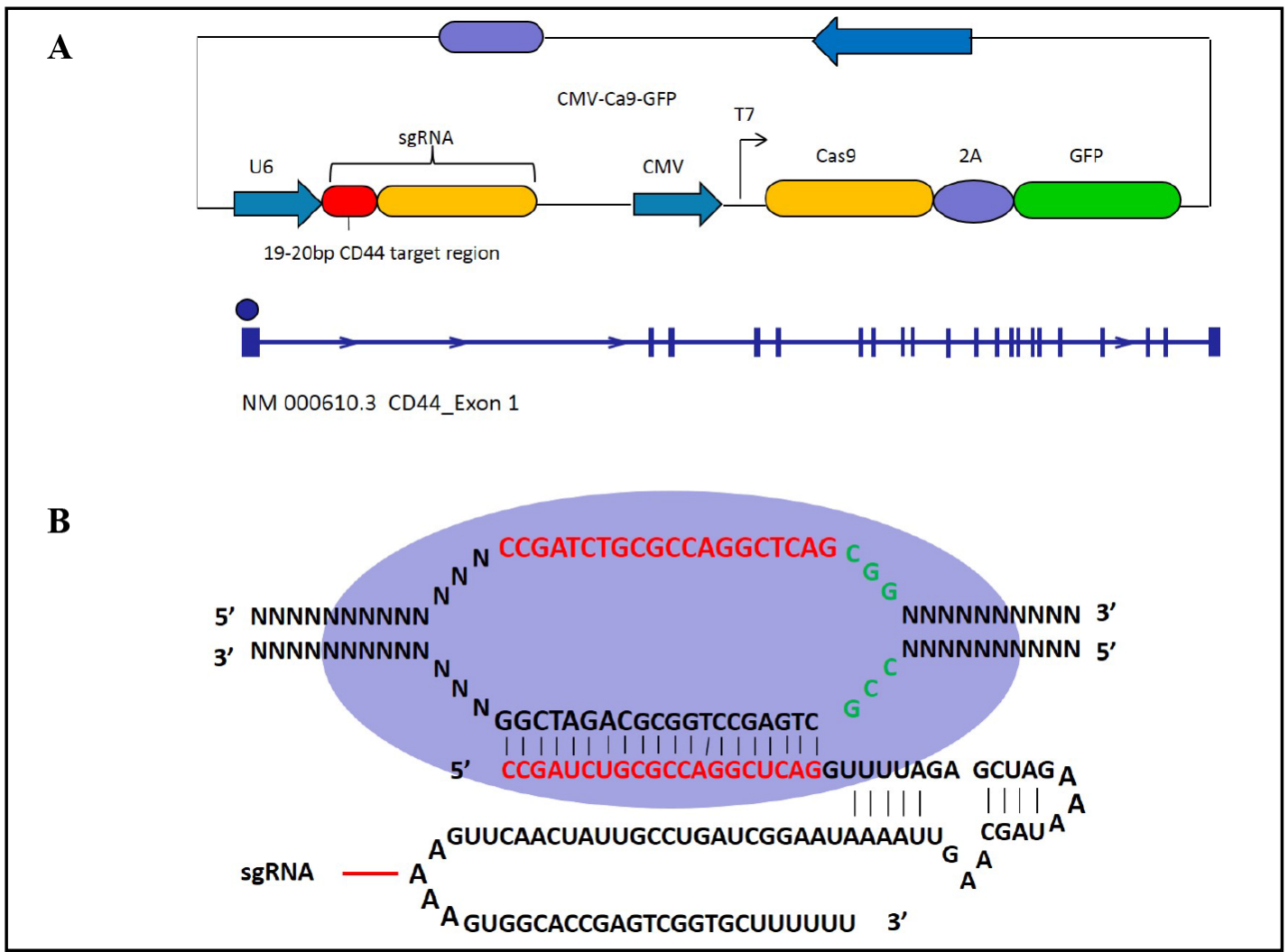

Fig. 1. (A) Elementary diagram of U6 CD44 sgRNA-CMV Cas9-GFP expression cassette in the single plasmid system. U6 is the promoter of sgRNA, and CMV promoter is used to induce expression of Cas 9 and GFP proteins. The targeted for sgRNA design of CD44 lies in the first exon with in the CD44 gene. (B) Schematic structure of CRISPR-Cas9 system functions on targeting the CD44 gene. The red fonts show sgRNA sequence, and green fronts indicate the PAM sequence.
Table 2. Characteristics of the study osteosarcoma patients

\begin{tabular}{lc}
\hline Characteristic & Number \\
\hline Tumor original site & 24 \\
Distal femur & 24 \\
Proximal tibia & 13 \\
Proximal humerus & 6 \\
Others & 13 \\
Age at onset & \\
$0-10$ & 5 \\
$11-20$ & 24 \\
$21-30$ & 21 \\
$>30$ & 6 \\
Gender & \\
Male & 30 \\
Female & 26 \\
Stages & \\
primary & \\
metastatic & 56 \\
recurrent & 30 \\
Treatment status & 11 \\
Pre-operative chemotherapy & 53 \\
No pre-operative chemotherapy & 3 \\
\hline
\end{tabular}




\section{Cellular Physiology Cell Physiol Biochem 2018;51:1879-1893 \begin{tabular}{ll|l} 
DOI: 10.1159/000495714 & O 2018 The Author(s). Published by S. Karger AG, Basel \\
www.karger.com/cpb
\end{tabular}}

Xiao et al.: Targeting CD44 in Osteosarcoma

\section{Fluorescence microscope observation}

To verify the transfection efficiency of recombinant plasmids in U-20SR2 and KHOSR2 cells, the expression level of GFP protein in osteosarcoma cell lines was detected by fluorescence microscopy. Firstly, U-2OSR2 cells and KHOSR2 cells were inoculated into 12 -well plates at a density of $1.0 \times 10^{5}$ cells $/ \mathrm{mL}$. And then the cells were transfected with CD44-Cas9-GFP or pEGFP-N3 plasmid. After incubated for 48 hours, the transfection efficiency was detected by a Nikon Eclipse Ti-U fluorescence microscope (Nikon Instruments, Inc., NY) equipped with a SPOTRT digital lens from Diagnostic Instruments, Inc. (Sterling Heights, MI).

\section{Western blotting}

The expression of CD44 protein in U-2OSR2 and KHOSR2 cells was measured by Western blotting after transfection of CD44-Cas9-GFP plasmids into osteosarcoma cells. Protein lysates of osteosarcoma cells were extracted with 1x RIPA lysis buffer. And then Protein Assay Reagent (Bio-Rad, Hercules, CA, USA) and a SPECTRA max Microplate Spectrophotometer from Molecular Devices (Sunnyvale, CA, USA) were used to detect the protein concentrations. The primary antibodies for CD44 (1:1000 dilution), P-gp (1:1000 dilution) and Cas9 (1:1000 dilution) were purchased from Cell Signaling Technology (Danvers, MA, USA). Secondary antibodies IRDye OR 800CW or IRDyeOR 680LT were purchased from LI-COR Biosciences (Lincoln, NE, USA). Odyssey Infrared Imaging System was used to scan Membrane signals and Odyssey 3.0 software analysis (LI-COR Biosciences, NE, and USA) was used to analyze gray value.

\section{Wound healing assay}

To assess the influence of CD44 knockout on migration of the osteosarcoma cells, wound healing assay was performed. U-20SR2 cells and KHOSR2 cells, which were transfected with or without CD44-Cas9-GFP or pEGFP-N3 plasmids, were inoculated into 12 -well plates at a density of $1.0 \times 10^{5}$ cells $/ \mathrm{mL}$. When the cell reached $80 \%$ confluence, three parallel lines with the same width across the same position in each plate well was created by sterile $200 \mu \mathrm{l}$ pipette tips. The well was washed once to remove the cell debris and suspend cells, and replace with conventional PRMI 1640 medium. The cells were given 24 hours to close the wounds. The well was observed under microscope (Nikon) at $100 \mathrm{X}$ magnification every 12 hours $(0,12$, 24 hours) and images were captured. Migration rate of the transfected cells was calculated by measuring the traveling distance of cells toward the center of the wound at each time interval.

\section{Matrigel invasion assay}

Matrigel invasion assay was used to examine the changes of cell invasion activity with a BD BioCoatTMMatrigelTM Invasion Chamber (Becton-Dickinson, MA, USA) according to the manufacturer's recommendations. Firstly, we put $5 \times 10^{4}$ cells without FBS or antibiotics into the upper chamber of each well. $500 \mu \mathrm{L}$ medium containing 10\% FBS without antibody was added to the bottom chambers. After being incubated for 24 hours, non-invading cells were carefully swept from the upper surface of the Martrigel filter using a cotton swab. Then, the membrane was immobilized with a $100 \%$ methanol and dyed with hematoxylin and reddish, subsequently, the number of cells passing through the Martrigel filter was observed under a microscope using a $100 \times$ objective.

Examination the spheroid formation of osteosarcoma cell in 3D suspension culture after knockout CD44

Osteosarcoma cell 3D suspension culture was carried out under the guidance of HDP 1096 Perfecta3D $®$ 96-Well Hanging Drop Plates Protocol (3D Biomatrix). Initially, in order to maintain the humidity condition of spheroid culture required for cell 3-D suspension culture, the preheated agarose solution was filled in orifice plates. Cell suspension $\left(2.5 \times 10^{5} / \mathrm{ml}\right)$, containing KHOSR2 and U-2OSR2 cells transfected with CD44Cas-GFP or pEGFP-N3 or non-transfected cells was prepared respectively. Hanging drops were made by pipetting $40 \mu \mathrm{l}$ cell suspension to each plate well. Then $10 \mu \mathrm{L}$ fresh medium was added to the cell suspension every other day to ensure the nutritional supply of cells. After 5 days, $100 \mu \mathrm{L}$ phosphate buffered saline (PBS) was carefully pipetted into each plate well with the morphology of the spheroids being intact. We collected these cells from the bottom of the plate. Finally, incubation was performed in $1 \mu \mathrm{L}$ Horchest for 15 minutes, and the spheres formed by 3-D suspension culture were observed under a Nikon Eclipse Ti-U fluorescence microscope. 


\section{Cellular Physiology Cell Physiol Biochem 2018;51:1879-1893 and Biochemistry Published \begin{tabular}{l|l} 
DOI: 10.1159/000495714 & (c) 2018 The Author(s). Published by S. Karger AG, Basel \\
www.karger.com/cpb
\end{tabular} \\ Xiao et al.: Targeting CD44 in Osteosarcoma}

MTT assay

Drug resistance of osteosarcoma cells to doxorubicin was determined by MTT assay. Each well of the 96-well culture plates was seeded with $3 \times 10^{3}$ KHOSR2 or U-2OSR2 cells which were transfected with pEGFP-N3 or CD44-Cas9-GFP and non-transfected (control). Then increasing concentrations of doxorubicin were used to treat the cells for the following 5 consecutive days. Thereafter, $20 \mu \mathrm{l}$ of MTT ( $5 \mathrm{mg} / \mathrm{mL}$ in PBS, Sigma-Aldrich, MO, USA) was added to each well of the 96-well culture plates and the plates were placed in a $37^{\circ} \mathrm{C}$ incubator for the next 4 hours. Finally, we used acid $(\mathrm{HCl})$-isopropanol to dissolve the product and SPECTRA max microplate spectrophotometer from Molecular Devices (Sunny Wale, CA, USA) to read the absorbance at wave length $490 \mathrm{~nm}$. The experiment was conducted in triplicate. Dose response curves were performed using GraphPad PRISM 5 software (La Jolla, CA).

\section{Drug uptake assay determined by fluorescence microscopy}

For visualisation the intracellular accumulation level of doxorubicin in osteosarcoma cell lines transfected with or without CD44-Cas9-GFP plasmids, $2 \times 10^{4}$ cells were seeded in 12 well plates repeatedly the day before the assay. The cells were then incubated with $10 \mu \mathrm{M}$ doxorubicin in RPMI-1640 medium for 2 hours at $37^{\circ} \mathrm{C}$. After washing the cells with PBS, nuclei were stained by $1 \mu \mathrm{g} / \mathrm{ml}$ Hoechst. Images were acquired with a Nikon Eclipse Ti-U fluorescence microscope equipped with a SPOT RT digital camera [59].

\section{Results}

\section{Expression of CD44 in osteosarcoma tissues}

To explore the potential roles of CD44 in osteosarcoma, we determined the expression of CD44 in human osteosarcoma tissues. CD44 staining was detected in 97 samples from 56 patients, which consisted of 56 primary samples, 30 metastatic samples and 11 recurrent samples. Firstly, we assessed the clinico-pathologic features of the human osteosarcoma samples and no significant correlation was found between CD44 expression level and other factors like tumor original site, age at onset, or gender (Fig. 2A-C). As the tissue immunohistochemistry result showed, all osteosarcoma tissue samples expressed different levels of CD44 on the cell membrane. No significant difference of the overall mean CD44 immunostaining scores were observed in metastatic and recurrent osteosarcoma tissues $(P>0.01)$ (Fig. 2D). However, expression level of CD44 in primary osteosarcoma tissue was significantly lower than that in metastatic and recurrent osteosarcoma tissues $(P<0.01)$ (Fig. 2D). Representative CD44 expression of different osteosarcoma tissue samples can be seen in Fig. 2E.

The connection of CD44 expression with osteosarcoma chemotherapy response and overall survival

In order to clarify the clinical relevance between CD44 expression and osteosarcoma, we studied the relationship of CD44 expression and osteosarcoma prognosis. Among the 56 primary osteosarcoma tissues, 53 tissues were from patients who had received pre-operative chemotherapy. The proportion of tumor necrosis was evaluated after surgical resection. Previous studies have indicated that a good chemotherapy response is that more than $90 \%$ excised tumor is necrotic tissue, otherwise it is defined as poor response. Among the cases included, 38 patients had a good response to chemotherapy drugs, while 15 patients showed poor response, and the remaining 3 patients had no pre-operative chemotherapy, so we didn't assess the necrotic areas (Table 1, Fig. 2F). The data showed significantly lower expression levels of CD44 in poor response osteosarcoma patients than in good response counterparts. Furthermore, we collected clinical information of patients with osteosarcoma, including follow-up months, to perform survival analysis (Table 2). The results showed that the overall survival for patients in the CD44 strong-staining group was significantly worse than for those in the CD44 weak-staining group $(P<0.01$, Fig. $2 \mathrm{G})$. The expression level of CD44 was scored according to an immunohistochemistry experiment. Score 0 to $1+$ is classified as weak, score $2+$ to $3+$ is classified as strong. 


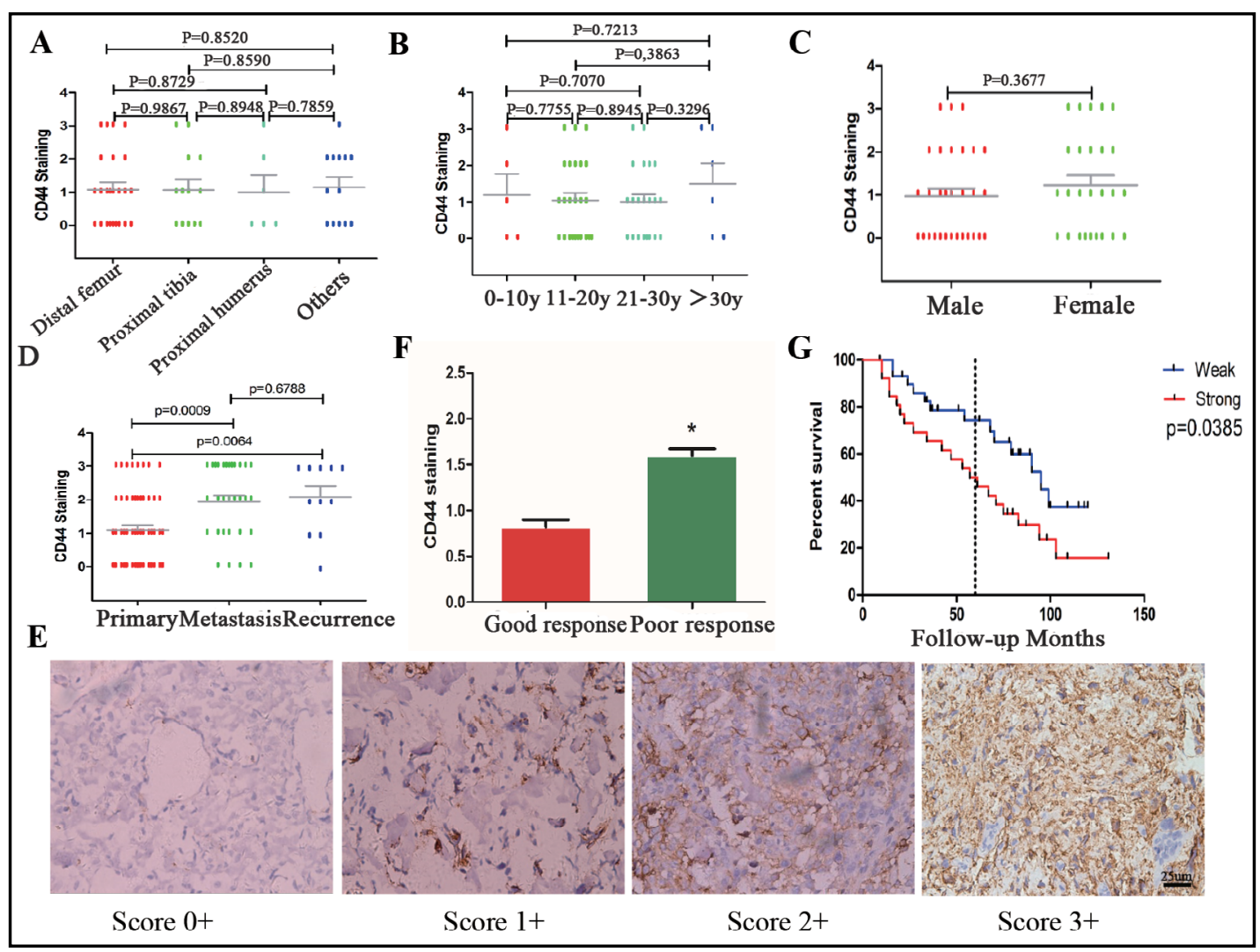

Fig. 2. Expression of CD44 in osteosarcoma tissues and relationship among expression of CD44 chemotherapy response and overall survival. A. Correlation between expression of CD44 and osteosarcoma original location. B. Correlation between expression of CD44 and age at onset of osteosarcoma. C. Correlation between expression of CD44 and gender, D. Differences of CD44 immunohistochemical staining scores in primary, metastatic, and recurrent osteosarcoma tissues. E. Representative pictures of CD44 expression in osteosarcoma tissues. F. The association between necrosis percentage and CD44 expression in preoperative chemotherapy. G. Association between expression of CD44 and overall survival in osteosarcoma patients.

\section{Knockout of CD44 by CRISPR-Cas9 in drug resistant osteosarcoma cells}

CD44 is expressed in drug-resistant osteosarcoma cell lines (KHOSR2 and U-20SR2 cells)[9]. In this study, we further studied the biological function of CD44 in KHOSR2 and U-20SR2 cells. In order to examine whether the CD44-Cas9-GFP (green fluorescent protein) or pEGFP-N3 plasmid is successfully transfected into KHOSR2 and U-2OSR2 cell, a fluorescence microscope was used. As showed in Fig. 3A, GFP expression can be detected in KHOSR2 and U-2OSR2 cells transfected with the plasmids, which suggested a successful introduction of CD44-Cas9-GFP and pEGFP-N3 plasmids into KHOSR2 and U-20SR2 cells.

Western blot was performed to further estimate whether CRISPR-Cas9 system could suppress CD44 expression in osteosarcoma cells. P-gp is considered as an important factor in the drug resistance degree of osteosarcoma cell line [26]. Hence, we also detected the expression of P-gp to examine the relationship between P-gp and CD44 in protein level. The experiments indicated that CD44 and P-gp were overexpressed in drug resistant cell (KHOSR2 and U-20SR2) un-transfected with CD44-Cas9-GFP. While after cells were transfected with CD44-Cas9-GFP, the expression of CD44 and P-gp was significantly decreased $\left({ }^{*} P<0.01\right.$ Fig. 3B \& 3C). And as expected, the expression of Cas9 protein was observed in KHOSR2 and U-20SR2 cells transfected with CD44-Cas9-GFP (Fig. 3B). The data above revealed that CRISPR-Cas9 system could effectively knockout CD44, and down-regulation of CD44 expression inhibited the P-gp expression. 
Knockout of CD44 by CRISPR-Cas9 repressed the migration and invasion activities of osteosarcoma cells

Migration and invasion are important pre-conditions for osteosarcoma metastasis. In this study, we knocked out CD44 by CRISPR-Cas9 system to explore its roles in the regulation of migration and invasion in osteosarcoma cells. In the wound healing assay, KHOSR2 and U-20SR2 cells un-transfected with CD44-Cas9-GFP plasmids were substantially covered with scratches after 24 hours of migration. However, compared with above cells, the migration capability of cells transfected with CD44-Cas9-GFP was significantly inhibited $(P<0.01$, Fig. 4A \& 4B). Moreover, transwell invasion assays results showed that the mean number of KHOSR2 and U-2OSR2 cells transfected with CD44-Cas9-GFP invading through the Martrigel filter was significantly less than that of the cells transfected with or without pEGFP-N3 plasmids $\left({ }^{*} P<0.01\right.$, Fig. $\left.4 \mathrm{C} \& 4 \mathrm{D}\right)$. Taken together, the two assays suggested that knockout of CD44 dramatically decreased the migratory and invasive capabilities of KHOSR2 and U-2OSR2 cells

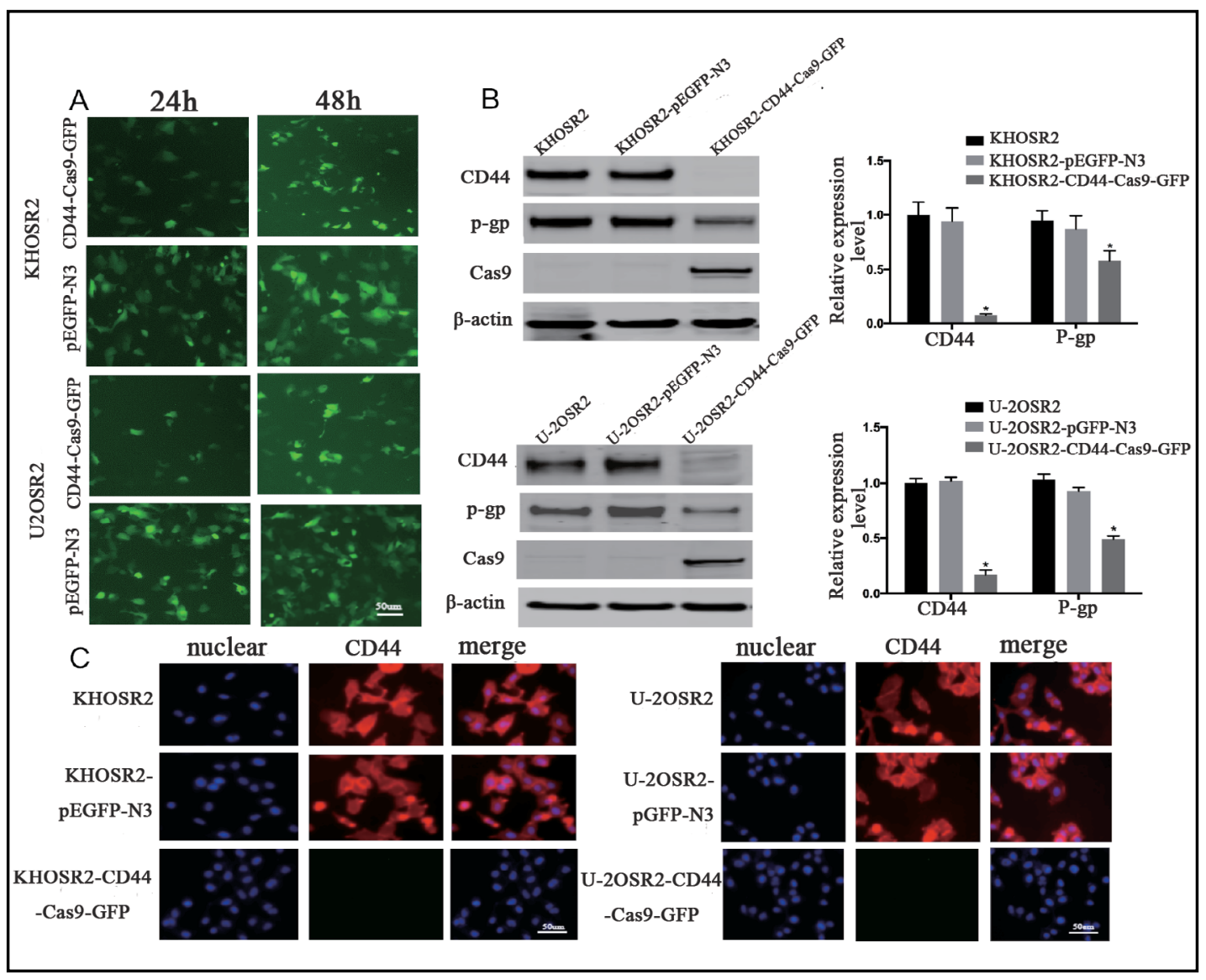

Fig. 3. Transfection of CD44 sgRNA-Cas9-GFP significantly inhibits CD44 expression. A. Fluorescence analysis show that most of KHOSR2 and U-20SR2 cells transfected with CD44-Cas9-GFP or pEGFP-N3 plasmids contain green fluorescence, which suggests that KHOSR2 and U-2OSR2 cells were successfully, introduced CD44-Cas9-GFP or pEGFP plasmids. This assay was repeated three times. B. Western blots showing CD44-Cas9-GFP system could effectively knock out CD44. The western bolt was performed in triplicate. C. Immunofluorescence photos for CD44 (red) and nuclei (blue) of KHOSR2 and U-2OSR2 cells transfected with CD44-Cas9-GFP plasmids. This assay was repeated twice. 
Fig. 4. Knockout of CD44 repress the migration and invasion activity of KHOSR2 and U-20SR2cells. A and $\mathrm{B}$. The relative migration distance of KHOSR2 and U-2OSR2 cells at different time points ( 0 hour, 12 hours, 24 hours) when transfected with CD44-Cas9-GFP and CD44 pEGFP-N3. The wound healing assay was conducted in duplicate.C and D. The invasion activity of KHOSR2 and U-2OSR2 cells, the matrigel invasion assay was repeated three times.

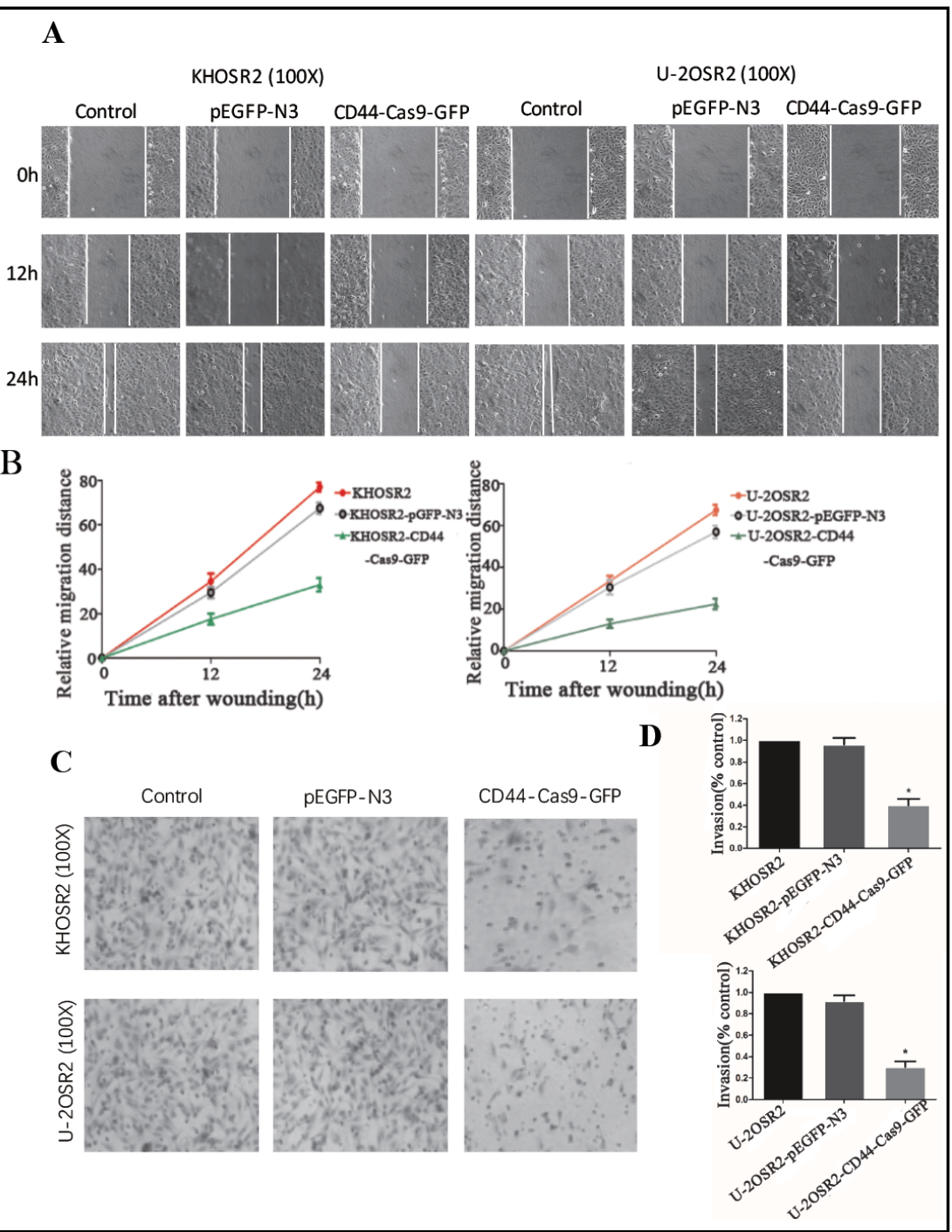

Knock out of CD44 by CRISPR-Cas9 repressed the spheroid formation in 3D culture of osteosarcoma cells

In order to imitate an in vivo environment and detect the effect of CD44 on osteosarcoma proliferation, a 3D cell culture was performed. After a 5-day culture in the 3D environment, the diameter of spheroids formed by KHOSR2 and U2OSR2 cells with CD44-Cas9-GFP intervention was significantly smaller than spheroids of cells transfected or un-transfected pEGFP-N3 plasmid $\left({ }^{*} P<0.01\right.$, Fig. 5$)$. The 3D cell culture indicated that CD44 can promote the proliferation of KHOSR2 and U-2OSR2 cells.

Knockout of CD44 expression by CRISPR-Cas9 inhibits osteosarcoma cell drug resistance to doxorubicin

Doxorubicin resistance is common in the treatment of osteosarcoma. In this study, the MTT assay was applied to evaluate the role of CD44 on drug resistance in the established cell lines induced by doxorubicin (KHOSR2 and U-20SR2 cells). The IC50 of doxorubicin in KHOSR2 cells transfected with CD44-Cas9-GFP was $0.92 \mu \mathrm{M}$. While the IC50 of doxorubicin in KHOSR2 cells un-transfected with CD44-Cas9-GFP plasmid was $2.8 \mu \mathrm{M}$. The IC50 of doxorubicin in U-20SR2 cells with CD44-Cas9-GFP intervention was $1.8 \mu \mathrm{M}$. Nevertheless, the IC50 of doxorubicin in U-20SR2 cells transfected or un-transfected pEGFP-N3 plasmid was $4.8 \mu \mathrm{M}$ and $5.9 \mu \mathrm{M}$, respectively $(P<0.01$, Fig. $6 \mathrm{~A})$. Further analysis of the MTT data 
Fig. 5. CD44-Cas9GFP transduction suppressed sphere formation of KHOSR2 and U-20SR2 cells in three-dimensional culture. The diameter of spheroids of cells transfected with CD44-Cas9-GFP was significantly smaller than that of cells transfected with or without transfection of pEGFP-N3. The assay was conducted

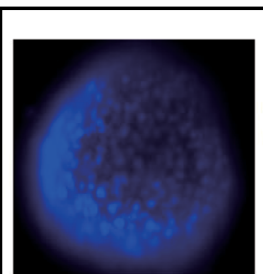
KHOSR2-untreated $(200 x)$

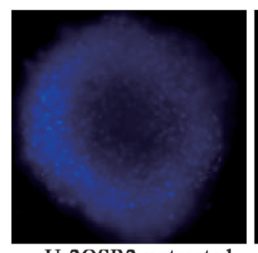

U-2OSR2-untreated $(200 \times)$

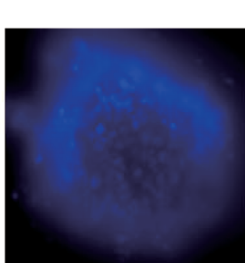

KHOSR2-pEGFP-N3 KHOSR2-CD44-Cas9-GFP $(200 x) \quad(200 x)$

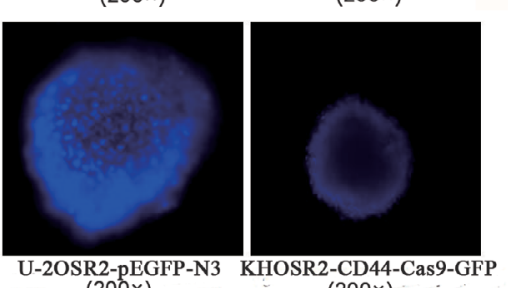

(200x)

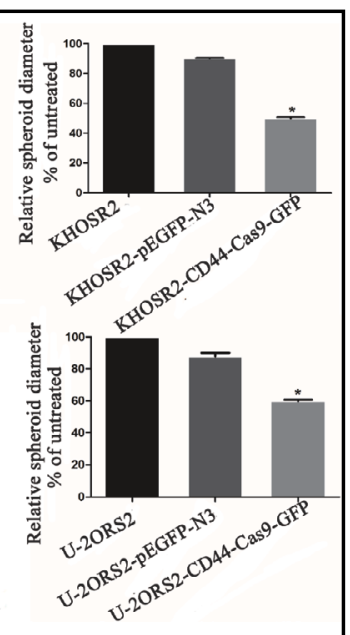

in three times.

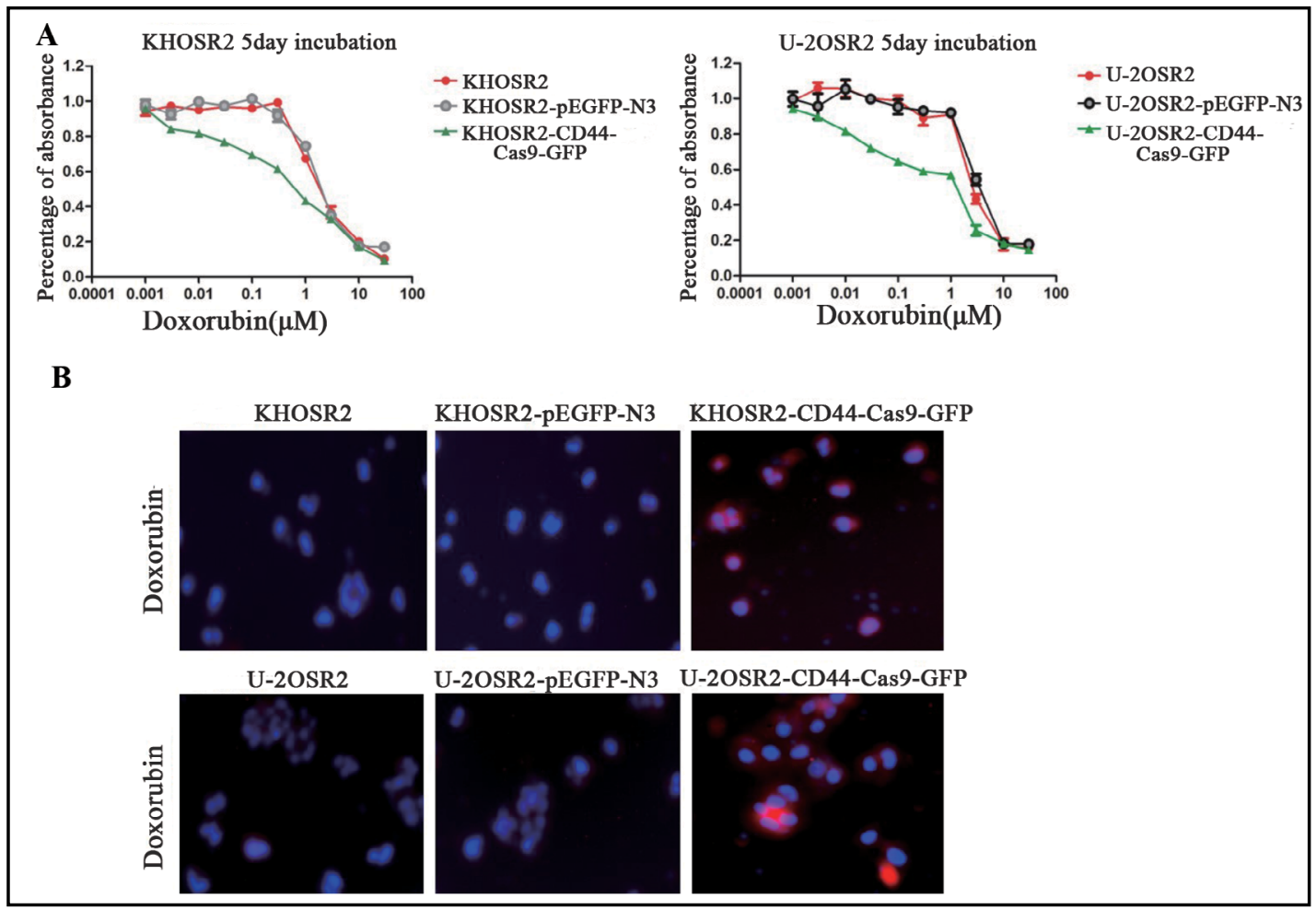

Fig. 6. The effect of down-regulating CD44 by CRISPR-Cas9 system on the drug sensitivity in osteosarcoma cells. A. Analysis of drug sensitivity of osteosarcoma cells by MTT assay. The MTT assay was conducted in triplicate. B. Drug intracellular accumulation images of osteosarcoma cell lines incubated with doxorubicin (Red). Compared with KHOSR2 or U-2OSR2 cells transfected with or without pEGFP-N3, intracellular adsorption of doxorubicin was significantly increased in KHOSR2-CD44-Cas9-GFP cells and U-20SR2CD44-Cas9-GFP cells. This assay was repeated three times.

demonstrated that knockout of CD44 significantly restored the sensitivity of osteosarcoma cells to chemotherapeutic drug doxorubicin. In order to clarify the MTT results, drug uptake assays were performed. The results showed that knockout of CD44 could significantly increase intracellular adsorption of doxorubicin in KHOSR2 and U-2OSR2 cells $(P<0.01$, Fig. 6B), which is in line with MTT result.

\section{KARGER}




\section{Cellular Physiology Cell Physiol Biochem 2018;51:1879-1893 and Biochemistry Published \begin{tabular}{l|l} 
DOI: 10.1159/000495714 & (c)18 The Author(s). Published by S. Karger AG, Basel \\
www.karger.com/cpb
\end{tabular} \\ Xiao et al.: Targeting CD44 in Osteosarcoma}

\section{Discussion}

In this study, we examined primary, metastatic and recurrent tissue samples of osteosarcoma patients and found that high expressions of CD44 were associated with metastasis and recurrence of osteosarcoma. Survival analysis indicated that CD44 can be considered as a predictor for overall survival and chemotherapy response in osteosarcoma patients. Then we successfully established a CD44 CRISPR/Cas9 system and generated osteosarcoma cell lines with constitutive knockout of CD44 expression to study the biological function of CD44. By CRISPR/Cas9 system, CD44 has been verified to mediate osteosarcoma cell migration, invasion, proliferation ability and drug resistance to doxorubicin. Furthermore, silencing CD44 by CRISPR/Cas9 decreased the expression of P-gp that is a drug-resistance marker. CD 44 CRISPR/Cas9 system maybe a potential therapeutic approach for the treatment of osteosarcoma in the future.

CD44 is a significant cancer stem cell (CSC) marker for a number of tumor entities, such as breast, colon, gallbladder, stomach, liver, ovary, pancreas, prostate cancers [27]. The expression of CD44 in metastatic ovarian cancer cells was significantly higher than that in primary ovarian cancer cells [28]. CD44 has been shown to be associated with tumor migration and metastasis in colon cancer and breast cancers, and could be used as a prognostic indicator in lung cancer [29-31]. CD44 is the major cellular receptor for HA and in association with HA, CD44 has a certain impact on the activation of cell-survival antiapoptotic proteins, consequently resulting in tumor cell proliferation and tumorigenesis in hepatocellular carcinoma and lung cancers $[6,32,33]$. Studies showed that overexpression of CD44 on tumor cells enhances the invasiveness of tumor by increasing affinity with its extracellular matrix ligand $\mathrm{HA}[9,27,34]$. And a study concentrated on ovarian cancer shows that when CD44 on the surface of ovarian cancer cells binds to HA on mesothelial cells, peritoneal metastasis may be triggered [35]. According to a previous in vivo investigation, CD44-HA interaction increased formation of lung metastasis of osteosarcoma in mice with severe combined immune deficiency[SCID)[34]. To test the role of the CD44 gene in tumorigenesis, mice with CD44 knockout were used. Although the silencing of CD44 had no effect on tumor incidence or survival, mice with knockout CD44 showed virtually aborted metastasis formation of osteosarcomas [36].

Though high expression of CD44 is closely associated with poor prognosis of osteosarcoma patients, there was a lack of an effective tool to target CD44 to further explore its biological function in the osteosarcoma. Previous studies have noted that knockdown CD44 by shRNA in osteosarcoma cell lines (U2-OS, KHOS) could efficiently decrease the osteosarcoma potential to metastasis [37]. However, the effect of knocking out targeted gene by RNAi-based techniques is neither permanent nor complete [9]. And it is limited to specific organisms with proper host mechanisms and may sometimes exhibit significant off-target effects and toxicity [38]. As CRISPR-Cas9 system is capable of precise modification of specific genomic locus by sgRNA, it may provide a potential platform for targeted gene regulation [39]. Due to the fact that CRISPR-Cas9 is an exogenous system, it does not compete with endogenous processes compared to siRNA. Furthermore, it works at DNA-base which is distinct from that of RNAi at mRNA level $[38,40]$. Thus CRISPR-Cas9 genome editing system can permanently knock out the target gene [41-43]. In squamous cell carcinoma, the amounts of CD44 mRNA in drug-sensitive and drug-resistant cell lines was not significantly different, but the expression of CD44 protein was significantly lower in sensitive cell lines than in resistant cell lines, which indicated if genome editing tools act on RNA levels, the relative protein expression does not always change [44]. With the development of largescale DNA oligonucleotide synthesis techniques, it is fast and inexpensive to generate a large collection of oligonucleotides containing a unique $20 \mathrm{bp}$ region which is essential for the Cas 9 protein recognizes the double-stranded DNA target gene [38]. In conclusion, the CRISPR- Cas9 system has great promise as a novel genome editing tool, which is suitable for various biomedical researches and clinical applications. 


\section{Cellular Physiology Cell Physiol Biochem 2018;51:1879-1893 \begin{tabular}{ll|l} 
and Biochemistry & $\begin{array}{l}\text { DOl: 10.1159/000495714 } \\
\text { Published online: } 1 \text { December } 2018\end{array}$ & $\begin{array}{l}\text { O } 2018 \text { The Author(s). Published by S. Karger AG, Basel } \\
\text { www.karger.com/cpb }\end{array}$ \\
\cline { 2 - 3 }
\end{tabular} \\ Xiao et al.: Targeting CD44 in Osteosarcoma}

CRISPR-Cas9 guided gene silencing is highly specific [38]. Our study also showed that CRISPR/Cas9 system could specifically and effectively knockout CD44 expression in osteosarcoma cells. In addition, we established stable CD44 knockout osteosarcoma cell lines at the DNA level successfully and further studied in this study. In meningioma and gastric cancer, high CD44 expression was correlated with tumor cell proliferation and invasion [45, 46]. Previous study showed that siRNA-mediated knockdown of CD44 significantly attenuates migration, invasion and viability of osteosarcoma cells [37]. We have similar findings with the application of CD44 sgRNA CRISPR/Cas9. Furthermore, in order to accurately assess the effect of CD44 on osteosarcoma cell proliferation, stable CD44 knockout osteosarcoma cell lines were cultured in a 3-D environment. Compared to osteosarcoma cells un-transfected with CD44-Cas9-GFP, the diameter of spheroids formed under 3-D culture were effectively decreased in cells transfected with CD44-Cas9-GFP, which suggested that CD44 could enhance the proliferation speed of osteosarcoma cells.

The survival rate of patients with aggressive or metastatic osteosarcoma is still relatively low, which is mainly due to chemotherapeutic drug resistance [47]. CD44 expression is also considered as an important biomarker to predict the sensitivity of chemotherapy in ovarian cancer, fibrosarcoma and Gastric cancer [8, 46, 48]. And CD44 abnormal expression can directly affect the emergence of drug-resistant phenotype $[49,50]$. CD44 receptor levels in many drug-resistant cancer cells were significantly increased [51]. Parallel results showed that down-regulation of CD44 can restore the sensitivity of breast cancer stem cells to certain drugs [52]. A previous study proved that CD44 plays an important role in cell adhesion-mediated drug resistance through interaction with its ligand HA[53]. CD44 can serve as a potential target for the treatment of drug-resistant tumors [54]. Consistent with those data, our results showed that poor chemotherapeutic drugs response of osteosarcoma patients was correlated with high expression level of CD44, and down-regulation of CD44 increased the susceptibility of drug-resistant osteosarcoma cell lines to chemotherapeutic agent doxorubicin. In addition, the result of MTT assay showed that the IC50 of doxorubicin in KHOSR2 and U-20SR2 cells with CD44-Cas9-GFP intervention was lower than cells transfected or un-transfected pEGFP-N3 plasmid, which further demonstrated that CD44 played an important role in chemotherapy response of osteosarcoma. Similarly, immunofluorescence showed that after knocking-out of CD44, intracellular adsorption of doxorubicin was significantly increased in KHOSR2 and U-20SR2 cells. Putting together, we suggested that CD 44 maybe involved in the drug resistance of osteosarcoma, thus may be a potential target for clinical treatment.

P-gp is considered as an important factor in the drug resistance degree of osteosarcoma cell line [26]. Works by Susa et al. have found that the inhibition of P-gp expression can improve the sensitivity of osteosarcoma to drugs [26]. In addition, down regulation of P-gp could impair invasion of multidrug resistance (MDR) breast cancer cell [55]. Due to P-gp and CD44 were determinants of MDR and metastases, there may be a direct connection between the two molecules. A study focus on ovarian cancer found that after the suppression of CD44 protein by siRNA targeted to CD44 mRNA in cancer cells isolated from malignant ascites obtained from patients with advanced ovarian carcinoma, the mRNA expression of MDR1 was significant decreased, which suggested that the expression of CD44 mRNA was positively correlated with the expression of MDR1 mRNA[56]. CD44 could abolish ubiquitin E3-ligase(FBXO21) -directed degradation of P-gp, which is dependent on the CD44 phosphorylation state. Due to positive effect of CD44 on P-gp-mediated drug resistance, CD44 may served as a potential therapeutic target in P-gp positive cells [57]. In our study, we demonstrated that the expression of P-gp was significantly altered after knockout of the CD44 gene with CRISPR-Cas9, which suggested that CD44 may mediate tumor drug resistance via regulation P-gp expression. 


\section{Cellular Physiology Cell Physiol Biochem 2018;51:1879-1893 \begin{tabular}{ll|l} 
and Biochemistry & $\begin{array}{l}\text { DOI: 10.1159/000495714 } \\
\text { Published onlIne: 1 December } 2018\end{array}$ & $\begin{array}{l}\text { (c) } 2018 \text { The Author(s). Published by S. Karger AG, Basel } \\
\text { www.karger.com/cpb }\end{array}$ \\
\hline
\end{tabular}}

Xiao et al.: Targeting CD44 in Osteosarcoma

\section{Conclusion}

The results showed in this study refined our insights into the key role of CD44 in migration, invasion, recurrence, proliferation and chemoresistance of osteosarcoma. Moreover, this is the first time that the CRISPR / Cas9 system is applied to explore not only the migration and tumorigenesis of osteosarcoma, but also drug resistance of osteosarcoma. Our finding shows that CRISPR-Cas9 is an effective gene editing technology that can significantly suppress CD44 expression.

\section{Acknowledgements}

This work was supported by Hunan Provincial Natural Science Foundation of China (2018JJ2565), the National Natural Science Foundation of China $(81672176,81871783)$, and the National Natural Science Foundation of China for Youth (81702670).

\section{Disclosure Statement}

The authors declare no competing financial interests.

\section{References}

$>1$ Mirabello L, Troisi R, Savage S: Osteosarcoma incidence and survival rates from 1973 to 2004: data from the Surveillance, Epidemiology, and End Results Program. Cancer 2009;115:1531-1543.

- B Bielack S, Kempf-Bielack B, Delling G, Exner G, Flege S, Helmke K, Kotz R, Salzer-Kuntschik M, Werner M, Winkelmann W, Zoubek A, Jürgens H, Winkler K: Prognostic factors in high-grade osteosarcoma of the extremities or trunk: an analysis of 1,702 patients treated on neoadjuvant cooperative osteosarcoma study group protocols. J Clin Oncol 2002;20:776-790.

-3 Bacci G, Longhi A, Versari M, Mercuri M, Briccoli A, Picci P: Prognostic factors for osteosarcoma of the extremity treated with neoadjuvant chemotherapy: 15-year experience in 789 patients treated at a single institution. Cancer 2006;106:1154-1161.

4 Meyers P, Schwartz C, Krailo M, Kleinerman E, Betcher D, Bernstein M, Conrad E, Ferguson W, Gebhardt M, Goorin A, Harris M, Healey J, Huvos A, Link M, Montebello J, Nadel H, Nieder M, Sato J, Siegal G, Weiner M, Wells R, Wold L, Womer R, Grier H: Osteosarcoma: a randomized, prospective trial of the addition of ifosfamide and/or muramyl tripeptide to cisplatin, doxorubicin, and high-dose methotrexate. J Clin Oncol 2005;23:2004-2011.

5 Tammi R, Kultti A, Kosma V, Pirinen R, Auvinen P, Tammi M: Hyaluronan in human tumors: pathobiological and prognostic messages from cell-associated and stromal hyaluronan. Semin Cancer Biol 2008;18:288295.

-6 Yang G, Fan J, Xu Y, Qiu S, Yang X, Shi G, Wu B, Dai Z, Liu Y, Tang Z, Zhou J: Osteopontin combined with CD44, a novel prognostic biomarker for patients with hepatocellular carcinoma undergoing curative resection. Oncologist 2008;13:1155-1165.

7 Park J, Kim S, Kim H, Kim K, Choi E, Kang M: A reciprocal regulatory circuit between CD44 and FGFR2 via c-myc controls gastric cancer cell growth. Oncotarget 2016;7:28670-28683.

-8 Gao Y, Foster R, Yang X, Feng Y, Shen J, Mankin H, Hornicek F, Amiji M, Duan Z: Up-regulation of CD44 in the development of metastasis, recurrence and drug resistance of ovarian cancer. Oncotarget 2015;6:93139326.

-9 Gao Y, Feng Y, Shen J, Lin M, Choy E, Cote G, Harmon D, Mankin H, Hornicek F, Duan Z: CD44 is a direct target of miR-199a-3p and contributes to aggressive progression in osteosarcoma. Sci Rep 2015;5:11365.

10 Lv Y, Dai H, Yan G, Meng G, Zhang X, Guo Q: Downregulation of tumor suppressing STF cDNA 3 promotes epithelial-mesenchymal transition and tumor metastasis of osteosarcoma by the Wnt/GSK-3 $\beta / \beta$-catenin/ Snail signaling pathway. Cancer Lett 2016;373:164-173.

11 Mimeault M, Hauke R, Batra S: Recent advances on the molecular mechanisms involved in the drug resistance of cancer cells and novel targeting therapies. Clin Pharmacol Ther 2008;83:673-691. 


\section{Cellular Physiology Cell Physiol Biochem 2018;51:1879-1893

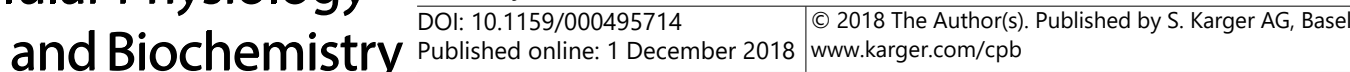

Xiao et al.: Targeting CD44 in Osteosarcoma

12 Choi Y, Yu A: ABC transporters in multidrug resistance and pharmacokinetics, and strategies for drug development. Curr Pharm Des 2014;20:793-807.

-13 Zorzos HS, Lazaris AC, Korkolopoulou PA, Kavantzas NG, Tseleni-Balafouta S, Patsouris ES, Tsavaris NV, Davaris PS: Multidrug resistance proteins and topoisomerase IIalpha expression in colon cancer: association with metastatic potential. Pathology 2003;35:315-318.

14 Nokihara H, Yano S, Nishioka Y, Hanibuchi M, Higasida T, Tsuruo T, Sone S: A new quinoline derivative MS-209 reverses multidrug resistance and inhibits multiorgan metastases by P-glycoprotein-expressing human small cell lung cancer cells. Japanese journal of cancer research : Gann 2001;92:785-792.

15 Bjornland K, Lehne G, Johansen HT, Fodstad O, Rugstad HE, Aasen AO, Ree AH: Human hepatoma cells rich in P-glycoprotein display enhanced in vitro invasive properties compared to P-glycoprotein-poor hepatoma cells. Oncology research 1998;10:255-262.

16 Miletti-González K, Chen S, Muthukumaran N, Saglimbeni G, Wu X, Yang J, Apolito K, Shih W, Hait W, Rodríguez-Rodríguez L: The CD44 receptor interacts with P-glycoprotein to promote cell migration and invasion in cancer. Cancer Res 2005;65:6660-6667.

17 Ravindranath AK, Kaur S, Wernyj RP, Kumaran MN, Miletti-Gonzalez KE, Chan R, Lim E, Madura K, Rodriguez-Rodriguez L: CD44 promotes multi-drug resistance by protecting P-glycoprotein from FBX021mediated ubiquitination. Oncotarget 2015;6:26308-26321.

18 A G: Silencing of CD44 gene expression in human 143-B osteosarcoma cells promotes metastasis of intratibial tumors in SCID mice. PLOS ONE 2013;8:e60329.

19 Barrangou R: RNA events. Cas9 targeting and the CRISPR revolution. Science 2014;344:707-708.

20 Ran F, Hsu P, Wright J, Agarwala V, Scott D, Zhang F: Genome engineering using the CRISPR-Cas9 system. Nat Protoc 2013;8:2281-2308.

-21 Jinek M, Chylinski K, Fonfara I, Hauer M, Doudna J, Charpentier E: A programmable dual-RNA-guided DNA endonuclease in adaptive bacterial immunity. Science 2012;337:816-821.

22 Mali P, Esvelt K, Church G: Cas9 as a versatile tool for engineering biology. Nat Methods 2013;10:957-963.

-23 Takayama K, Igai K, Hagihara Y, Hashimoto R, Hanawa M, Sakuma T, Tachibana M, Sakurai F, Yamamoto T, Mizuguchi H: Highly efficient biallelic genome editing of human ES/iPS cells using a CRISPR/Cas9 or TALEN system. Nucleic Acids Res 2017;45:5198-5207.

24 Nishimasu H, Ran F, Hsu P, Konermann S, Shehata S, Dohmae N, Ishitani R, Zhang F, Nureki O: Crystal structure of Cas9 in complex with guide RNA and target DNA. Cell 2014;156:935-949.

25 Liang C, Li F, Wang L, Zhang Z, Wang C, He B, Li J, Chen Z, Shaikh A, Liu J, Wu X, Peng S, Dang L, Guo B, He X, Au D, Lu C, Zhu H, Zhang B, Lu A, Zhang G: Tumor cell-targeted delivery of CRISPR/Cas9 by aptamerfunctionalized lipopolymer for therapeutic genome editing of VEGFA in osteosarcoma. Biomaterials 2017;147:68-85.

26 Susa M, Iyer A, Ryu K, Choy E, Hornicek F, Mankin H, Milane L, Amiji M, Duan Z: Inhibition of ABCB1 (MDR1) expression by an siRNA nanoparticulate delivery system to overcome drug resistance in osteosarcoma. PLoS ONE 2010;5:e10764.

27 Greve B, Kelsch R, Spaniol K, Eich H, Götte M: Flow cytometry in cancer stem cell analysis and separation. Cytometry A 2012;81:284-293.

28 Chen H, Hao J, Wang L, Li Y: Coexpression of invasive markers (uPA, CD44) and multiple drugresistance proteins (MDR1, MRP2) is correlated with epithelial ovarian cancer progression. Br J Cancer 2009;101:432-440.

29 Li G, Gao Y, Cui Y, Zhang T, Cui R, Jiang Y, Shi J: Overexpression of CD44 is associated with the occurrence and migration of non-small cell lung cancer. Mol Med Rep 2016;14:3159-3167.

30 Shinohara S, Hanagiri T, Taira A, Takenaka M, Oka S, Chikaishi Y, Uramoto H, So T, Yamada S, Tanaka F: Immunohistochemical Expression and Serum Levels of CD44 as Prognostic Indicators in Patients with NonSmall Cell Lung Cancer. Oncology 2016;90:327-338.

-31 Zhao S, He J, Qiu Z, Chen N, Luo Z, Chen B, Li W: Prognostic value of CD44 variant exon 6 expression in nonsmall cell lung cancer: a meta-analysis. Asian Pac J Cancer Prev 2014;15:6761-6766.

32 Heldin P, Karousou E, Bernert B, Porsch H, Nishitsuka K, Skandalis SS: Importance of hyaluronan-CD44 interactions in inflammation and tumorigenesis. Connective tissue research 2008;49:215-218.

-33 Noble PW, Jiang D: Matrix regulation of lung injury, inflammation, and repair: the role of innate immunity. Proceedings of the American Thoracic Society 2006;3:401-404.

-34 Gvozdenovic A, Arlt M, Campanile C, Brennecke P, Husmann K, Li Y, Born W, Muff R, Fuchs B: CD44 enhances tumor formation and lung metastasis in experimental osteosarcoma and is an additional predictor for poor patient outcome. J Bone Miner Res 2013;28:838-847.

-35 Sillanpaa S, Anttila MA, Voutilainen K, Tammi RH, Tammi MI, Saarikoski SV, Kosma VM: CD44 expression indicates favorable prognosis in epithelial ovarian cancer. Clinical cancer research : an official journal of the American Association for Cancer Research 2003;9:5318-5324. 


\section{Cellular Physiology Cell Physiol Biochem 2018;51:1879-1893 \begin{tabular}{l|l|l} 
and Biochemistry Published onlıne:1 1 December 2018 & $\begin{array}{l}\text { ○ } 2018 \text { The Author(s). Published by S. Karger AG, Basel } \\
\text { www.karger.com/cpb }\end{array}$ \\
\hline
\end{tabular} \\ Xiao et al.: Targeting CD44 in Osteosarcoma}

-36 Weber GF, Bronson RT, Ilagan J, Cantor H, Schmits R, Mak TW: Absence of the CD44 gene prevents sarcoma metastasis. Cancer research 2002;62:2281-2286.

-37 Mayr L, Pirker C, Lotsch D, Van Schoonhoven S, Windhager R, Englinger B, Berger W, Kubista B: CD44 drives aggressiveness and chemoresistance of a metastatic human osteosarcoma xenograft model. Oncotarget 2017;8:114095-114108.

-38 Qi LS, Larson MH, Gilbert LA, Doudna JA, Weissman JS, Arkin AP, Lim WA: Repurposing CRISPR as an RNAguided platform for sequence-specific control of gene expression. Cell 2013;152:1173-1183.

-39 Barrangou R, Fremaux C, Deveau H, Richards M, Boyaval P, Moineau S, Romero DA, Horvath P: CRISPR provides acquired resistance against viruses in prokaryotes. Science 2007;315:1709-1712.

40 Zamore PD, Tuschl T, Sharp PA, Bartel DP: RNAi: double-stranded RNA directs the ATP-dependent cleavage of mRNA at 21 to 23 nucleotide intervals. Cell 2000;101:25-33.

41 Zhou Y, Zhu S, Cai C, Yuan P, Li C, Huang Y, Wei W: High-throughput screening of a CRISPR/Cas9 library for functional genomics in human cells. Nature 2014;509:487-491.

42 Cong L, Ran FA, Cox D, Lin S, Barretto R, Habib N, Hsu PD, Wu X, Jiang W, Marraffini LA, Zhang F: Multiplex genome engineering using CRISPR/Cas systems. Science 2013;339:819-823.

-43 Tu Z, Yang W, Yan S, Guo X, Li XJ: CRISPR/Cas9: a powerful genetic engineering tool for establishing large animal models of neurodegenerative diseases. Mol Neurodegener 2015;10:35.

44 Cannistra SA, DeFranzo B, Niloff J, Ottensmeir C: Functional heterogeneity of CD44 molecules in ovarian cancer cell lines. Clinical cancer research : an official journal of the American Association for Cancer Research 1995;1:333-342.

45 Mostafa R, Khairy R: CD44 Expression in Meningioma and its Correlation with Proliferation Indices. J Clin Diagn Res 2017;11:EC12-EC15.

46 Senel F, Kokenek Unal TD, Karaman H, Inanc M, Aytekin A: Prognostic Value of Cancer Stem Cell Markers CD44 and ALDH1/2 in Gastric Cancer Cases. Asian Pacific journal of cancer prevention : APJCP 2017;18:2527-2531.

47 Chou A, Gorlick R: Chemotherapy resistance in osteosarcoma: current challenges and future directions. Expert Rev Anticancer Ther 2006;6:1075-1085.

48 Cain JW, Hauptschein RS, Stewart JK, Bagci T, Sahagian GG, Jay DG: Identification of CD44 as a surface biomarker for drug resistance by surface proteome signature technology. Molecular cancer research : MCR 2011;9:637-647.

49 Ozcelikkale A, Shin K, Noe-Kim V, Elzey B, Dong Z, Zhang J, Kim K, Kwon I, Park K, Han B: Differential response to doxorubicin in breast cancer subtypes simulated by a microfluidic tumor model. J Control Release 2017;266:129-139.

50 Zavros Y: Initiation and Maintenance of Gastric Cancer: A Focus on CD44 Variant Isoforms and Cancer Stem Cells. Cell Mol Gastroenterol Hepatol 2017;4:55-63.

51 Marhaba R, Klingbeil P, Nuebel T, Nazarenko I, Buechler M, Zoeller M: CD44 and EpCAM: cancer-initiating cell markers. Curr Mol Med 2008;8:784-804.

52 Van Phuc P, Nhan P, Nhung T, Tam N, Hoang N, Tue V, Thuy D, Ngoc P: Downregulation of CD44 reduces doxorubicin resistance of CD44CD24 breast cancer cells. Onco Targets Ther 2011;4:71-78.

53 Zhong Y, Zhang J, Cheng R, Deng C, Meng F, Xie F, Zhong Z: Reversibly crosslinked hyaluronic acid nanoparticles for active targeting and intelligent delivery of doxorubicin to drug resistant CD44+ human breast tumor xenografts. J Control Release 2015;205:144-154.

54 Vinogradov S, Wei X: Cancer stem cells and drug resistance: the potential of nanomedicine. Nanomedicine (Lond) 2012;7:597-615.

55 Zhang F, Zhang H, Wang Z, Yu M, Tian R, Ji W, Yang Y, Niu R: P-glycoprotein associates with Anxa2 and promotes invasion in multidrug resistant breast cancer cells. Biochemical pharmacology 2014;87:292-302.

-56 Shah V, Taratula 0, Garbuzenko 0, Taratula O, Rodriguez-Rodriguez L, Minko T: Targeted nanomedicine for suppression of CD44 and simultaneous cell death induction in ovarian cancer: an optimal delivery of siRNA and anticancer drug. Clin Cancer Res 2013;19:6193-6204.

57 Ravindranath A, Kaur S, Wernyj R, Kumaran M, Miletti-Gonzalez K, Chan R, Lim E, Madura K, RodriguezRodriguez L: CD44 promotes multi-drug resistance by protecting P-glycoprotein from FBX021-mediated ubiquitination. Oncotarget 2015;6:26308-26321.

58 Liu T, Li Z, Zhang Q De Amorim Bernstein K, Lozano-Calderon S, Choy E, Hornicek FJ, Duan Z: Targeting ABCB1 (MDR1) in multi-drug resistant osteosarcoma cells using the CRISPR-Cas9 system to reverse drug resistance. Oncotarget 2016;7:83502-83513.

59 Yang X, Yang P, Shen J, Osaka E, Choy E, Cote G, Harmon D, Zhang Z, Mankin H, Hornicek FJ, Duan Z: Prevention of multidrug resistance (MDR) in osteosarcoma by NSC23925 British journal of cancer 2014;110:2896-2904. 